\title{
KAJIAN INTERIOR BANGUNAN PADA PT. POS MEDAN
}

\author{
Juli Atika \\ Program Studi Desain Interior Fakultas Seni dan Desain \\ Universitas Potensi Utama \\ juliatika4@gmail.com
}

\begin{abstract}
ABSTRAK
Pembuatan interior bangunan pada PT. Pos Indonesia memerlukan berbagai aspek yang dapat di rancang dalam sebuah kenyamanan. PT Pos Indonesia (Persero) sebagai sebuah penyedia jasa di bidang pengiriman kini juga berubah dan melakukan berbagai pembenahan. Hal ini agar tidak ditinggalkan oleh para pelanggannya mengingat saat ini banyak sekali perusahaan pengiriman barang maupun perusahaan ekspedisi. Perusahaan tersebut bersaing makin kompetitif baik dari segi harga maupun pelayanan. Oleh karena itu, selain di bidang pengiriman, PT Pos Indonesia (Persero) melebarkan sayapnya di bidang yang lain. Untuk mengkaji dalam pembuatan interior bangunan ini, penulis menggunakan metode penelitian kualitatif, dimana metode ini adalah mengkaji salah satu interior bangunan yang ada di Pos Indonesia. Sehingga bisa dilihat bahwa kantor Pos Indonesia memiliki arsitektur eropa modern dan arsitektur lokal serta banyak elemen yangdigunakan dalam gedung itu mungkin sebuah menara, atap atas ornamen, gevel, atap berhias, motif didalam dan diluar tubuh bangunan kantor Pos tersebut.
\end{abstract}

Kata Kunci : Pos Indonesia, Medan, Interior, Bangunan

\begin{abstract}
Making building interiors at PT. Pos Indonesia requires various aspects that can be designed in a comfort. PT Pos Indonesia (Persero) as a service provider in the field of shipping is now also changing and making various improvements. This is so that it is not abandoned by its customers considering that there are many shipping companies and shipping companies. These companies compete more competitively both in terms of price and service. Therefore, in addition to shipping, PT Pos Indonesia (Persero) spread its wings in other fields. To study in making the interior of this building, the author uses qualitative research methods, where this method is to examine one of the interiors of buildings in Pos Indonesia. So that it can be seen that the post office of Indonesia has modern European architecture and local architecture and many elements used in the building may be a tower, roof over ornaments, gevels, ornate roofs, motifs inside and outside the post office building's body.
\end{abstract}

Keywords: Pos Indonesia, Medan, Interior, Buildings

\section{PENDAHULUAN}

Gedung kantor pos Medan merupakan salah satu bangunan kolonial cagar budaya dengan nilai-nilai arsitektur sangat menarik. Eksplorasi gedung ini masih sangat terbatas pada beberapa deskripsi fisik yang kurang mendalam serta tidak memperhatikan nilai-nilai arsitekturnya. Perkembangan Medan menjadi kota besar menerima banyak berbagai budaya lokal maupun asing seperti India, Cina dan Belanda. Hal ini semakin pesat terjadi ketika Belanda menguasai Medan dan sekitarnya, proses interaksi budaya dengan para 
pendatang semakin tinggi. Orang India, Arab maupun orang-orang asing dari daratan Cina didatangkan sebagai pekerja menempati Medan. Jejak-jejak alkulturasi budaya dalam konteks arsitektur ini dapat dilihat dari berbagai bangunan yang ada di sini. Pemerintah Belanda membangun kota ini baik secara fisik maupun sosial sebagai kota yang memiliki ciri ciri kota kolonial. Budaya kolonial Belanda yang dominan tidak serta merta menghapuskan lokalitas tersebut bahkan sebaliknya beradaptasi dengan budaya setempat. Keragaman tersebut membentuk karakter kota Medan yang pluralistik dan unik. Salah satu peninggalan kolonial di kawasan pusat kota Medan adalah gedung Kantor Pos Medan. [2]

Bangunan ini berada di depan lapangan Kesawan yang dulu bernama Esplanada. Sekilas bangunan ini nampak megah dan berbeda dengan berbagai bangunan kolonial lain yang ada di lingkungan tersebut. Gedung ini hingga sekarang masih dipakai sebagai wadah pelayanan pos. Menurut Luckmann pelayanan pos di Medan sudah ada sejak tahun 1879 atau 1883. Pada saat kantor pos dibangun, kota Medan sedang mengalami kemajuan yang sangat pesat. Hal ini tidak mengherankan karena Medan merupakan kota besar di Sumatera sehingga tidak mustahil berbagai aktivitas industry, perkebunan dan perdagangan sudah berkembang pesat dan membutuhkan layanan jasa pos. [1]

\section{STUDI LITERATUR}

Dalam penulisan makalah ini, penulis banyak melakukan studi literatur pada bukubuku, tesis, jurnal dan penelitian berkaitan tentang kajian interior terhadap PT. Pos Indonesia yang telah dilakukan oleh pengkarya sebelumnya. Data yang di dapat dari studi literatur ini digunakan sebagai acuan dalam membuat kajian terhadap interior bangunan. Tujuan dalam kajian interior ini terdapat beberapa ruangan yang akan dikaji dalam sebuah bangunan interior pada PT. Pos Indonesia yang ada di Medan.

Terdapat beberapa elemen didalam ruangan kantor Pos Indonesia termasuk salah satunya yaitu Interior suatu ruangan dibentuk melalui elemen-elemen pembentuk yang saling terkait. Elemen-elemen tersebut menjadi hal yang paling mendasar dalam perancangan interior suatu ruangan. [2] Adapun elemen-elemen interior terdiri dari:

1. Plafond: bagian dari interior yang berada di paling atas sebagai penutup ruang.

2. Dinding: bagian sari interior yang posisinya di tengah/mengelilingi/membentuk ruang sebagai pembatas ruang.

3. Lantai: bagian paling bawah dari ruangan sebagai alas ruang tersebut.

Menurut Francis D. K. Ching interior desain adalah Interior design is the planning, layout, and design of the interior spaces within buildings. These physical settings satisfy our basic need for shelter and protection,set the stage for and influence the shape of our activities, nurture our aspirations, express the ideas that accompany our actions, and affect our outlook, mood, and personality. The purpose of

interior design, therefore, is the functional improvement, aesthetic enrichment, and psychological enhancement of the quality of life in interior spaces. Definisi di atas menjelaskan bahwa desain interior adalah sebuah perencanaan tata letak dan perancangan ruang dalam di dalam bangunan. Keadaan fisiknya memenuhi kebutuhan dasar kita akan naungan dan perlindungan, mempengaruhi bentuk aktivitas dan memenuhi aspirasi kita dan mengekspresikan gagasan yang menyertai tindakan kita,disamping itu sebuah desain 
interior juga mempengaruhi pandangan, suasana hati dan kepribadian kita. Oleh karena itu tujuan dari perancangan interior adalah pengembangan fungsi, pengayaan estetis dan peningkatan psikologi ruang interior. Secara garis besar elemen interior yang dikaji dapat dijelaskan secara sebagai berikut : [2]

Elemen - Elemen Dasar Interior

1. Elemen Lantai Lantai merupakan salah satu elemen terpenting dalam sebuah interior. Lantai merupakan batas bawah bagi interior sebuah ruang. Lantai terbentang secara horisontal. Treatment yang dapat diterapkan pada lantai bermacam macam mulai dari penggunaan 2 berbagai material, pengaplikasiaan perbedaan ketinggian lantai, dan pengaplikasian esensi - esensi bentuk.

2. Elemen Dinding Dinding merupakan elemen interior yang membatasi interior ruang. Dinding terbentang secara vertikal dan merupakan bidang terbesar dalam interior ruang. Pengolahan dinding haruslah tepat karena dinding merupakan bidang dominan suatu interior ruang. Dinding dapat diaplikasikan dengan berbagai material finishing, material pembentuk, pencahayaan, dll.

3. Elemen Ceiling/ Langit - Langit Ceiling merupakan pembatas interior yang terbentang secara horisontal pada bagian teratas interior. Ceiling merupakan bagian interior yang pada umumnya tidak begitu diperhatikan oleh masyarakat awam, namun dengan diaplikasikannya beberapa desain tepat pada ceiling, dapat menimbulkan efek yang lebih baik. Treatment ceiling dapat berupa pengaplikasian berbagai material, perbedaan ketinggian, dan pengaplikasian bentuk bentuk pada ceiling.

4. Elemen Estetis Interior harus mengandung elemen estetis yang mengacu pada prinsip desain seperti proporsi, skala ruang, keseimbangan, harmoni ruang, kesatuan dan variasi ruang, irama ruang, penekanan ruang dan hal - hal keindahan seperti asesoris ruang.

5. Elemen Bukaan Bukaan pada elemen ruang adalah jendela, pintu, dan lubang sirkulasi. Dengan adanya bukaan, maka memungkinkan terjadinya pertukaran udara yang baik, sehingga ruangan menjadi nyaman dan sehat.

6. Elemen Cahaya Cahaya merupakan elemen interior yang tidak dapat dilupakan, tanpa adanya cahaya tidak akan ada kehidupan, dan manusia tidak dapat melihat. Interior ruang memerlukan pencahayaan yang cukup intensitasnya. Ambience ruang akan terbentuk dengan adanya pengaplikasian pencahayan dengan benar.

\section{PEMBAHASAN}

Terdapat tujuh prinsip dasar yang diwadahi dalam interior design, antara lain :[3]

\section{Unity and Harmony}

Yaitu suatu ruangan dianggap sebagai suatu kesatuan dimana semua elemen yang ada saling melengkapi dan berkesinambungan satu dengan yang lainnya sehingga menghasislkan komposisi yang seimbang.

2. Keseimbangan (Balance)

Keseimbangan berarti tidak "berat" sebelah. Tidak terlalu condong ke sisi sebelah kanan atau kiri atau atas dan sebagainya. Segala sesuatu yang seimbang akan menciptakan unity dan harmony.

Keseimbangan dibagi menjadi 3 yaitu:

- Keseimbangan Simetris: Keseimbangan simetris terjadi apabila berat visual dari 
elemen-elemen desain terbagi secara merata baik dari segi horizontal maupun vertikal. Gaya ini mengandalkan keseimbangan berupa dua elemen yang mirip dari dua sisi yang berbeda.

- Keseimbangan Asimetris: Keseimbangan asimetris terjadi ketika berat visual dari elemen desain tidak merata di poros tengah halaman. Gaya ini mengandalkan permainan visual seperti skala, kontras, warna untuk mencapai keseimbangan dengan tidak beraturan.

- Keseimbangan Radial: Adalah ketika semua element desain tersusun dan berpusat di tengah. Misalnya: Tangga berbentuk spiral.

3. Vocal Point

Vocal Point disini maksudnya adalah aksen yang menjadi daya tarik ruangan. Bisa satu atau lebih. Misalnya vocal point pada ruangan adalah jendela besar yang ada di ruangan, perapian atau bisa juga lukisan. Pemberian warna atau detail dan bentuk tertentu juga dapat dijadikan sebagai vocal point.

4. Ritme

Dalam desain interior, ritme adalah semua pola pengulangan tentang visual. Ritme didefinisikan sebagai kontinuitas atau pergerakan terorganisir.

5. Detail

Detail pada desain interior mencakup segala kelengkapan yang ada pada ruangan. Mulai dari furniture utama, furniture tambahan, hingga furniture artivasial. Detaildetail tersebut juga berpengaruh besar terhadap suasana ruang yang tercipta.

6. Skala dan Proporsi

Kedua prinsip desain yang berjalan beriringan, karena keduanya berhubungan dengan ukuran dan bentuk. Skala dan proporsi disini berpengaruh terhadap tingkat kenyamanan civitas yang berada di dalam ruangan.

7. Warna

Warna pada desain interior berpengaruh terhadap mood dan suasana ruang. Warnawarna yang soft akan cenderung menciptakan suasana ruang yang menenangkan, sedangkan warna-warna cerah akan memberikan suasana ruang yang menyegarkan.

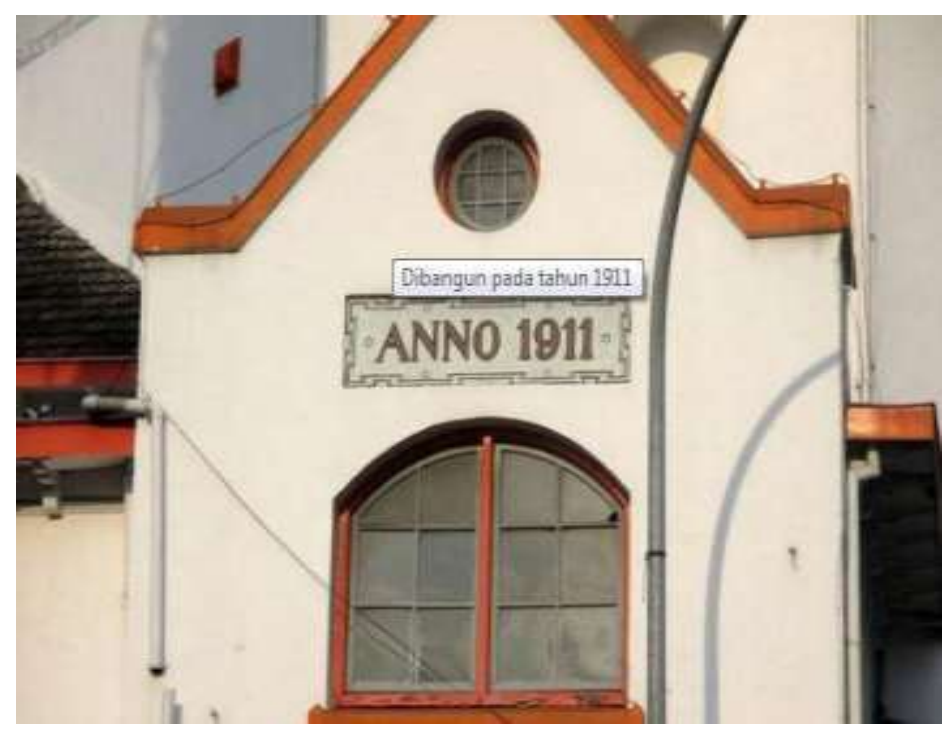

Gambar 1 : Sirkulasi Udara Pada PT. POS Indonesia

Sumber : Juli Atika, 2018 


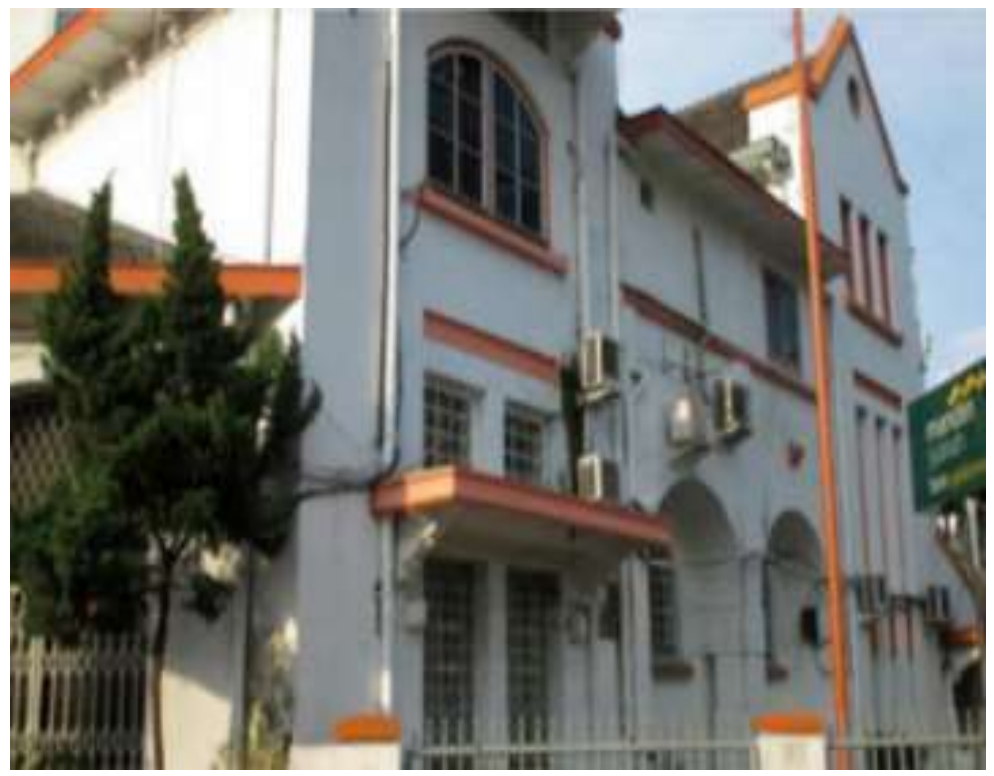

Gambar 2 : Arsitektur Kantor Pos Sumber : Juli Atika, 2018

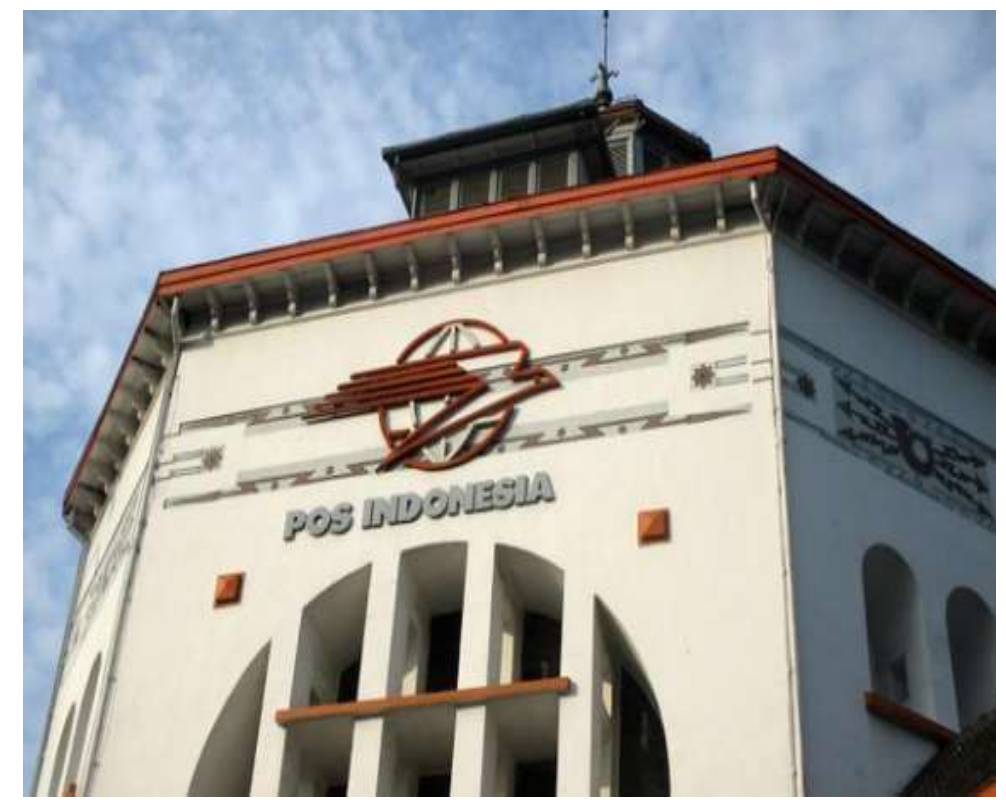

Gambar 3 : Logo Dari Kantor Pos Sumber : Juli Atika, 2018

Terdapat logo yang ada di atas pentilasi udara terkait logo dari kantor pos tersebut dan logo ini terdapat lambang burung yang artinya burung merpati terbang yang mengartikan bahwa seperti pesan kilat dalam sebuah pengiriman. Serta gambar-gambar yang lain menunjukan bahwa ruang arsitektur pada kantor pos masih seperti bagaimana bentuk pada aslinya hanya saja terdapat tambahan pada warna-warna agar terlihat lebih menarik. pada sirkulasi udara pada kantor pos tersebut yang membuat ruangan pada pos lebih segar dan tidak memerlukan alat bantu pendingin seperti AC agar bangunan terlihat lebih sejuk dan menarik pusat perhatian orang lain terkait kantor pos tersebut.

Bangunan ini didesain oleh Snuyf, Direktur Jawatan Pekerjaan Umum Belanda untuk Kesultanan Deli. Yang mulai dibangun pada 1909 hingga 1911 sesuai tulisan 'ANNO 1911' pada dinding bagian samping kiri dan kanan sebagai bukti kelahiran bangunan peninggalan Belanda tersebut.Arsitektur kantor pos sedikit berbeda dengan bangunan-bangunan tua 
peninggalan Belanda lainnya di Medan seperti Balai Kota dan Bank Indonesia yang masih ada desain klasik, yang identik dengan sulur-sulur dan bentuk lengkung. [1]

Sedangkan di kantor pos ini arsitekturnya lebih geometris dan sudah masuk ke era arsitektur modern. Di Eropa, desain bangunan seperti pada Kantor Pos Besar Medan dikenal dengan nama arsitektur modern fungsional. Jenis arsitektur ini adalah generasi ketiga setelah arsitektur klasik yang hadir sebelum 1910 dan neo-klasik sebelum 1920. Kedua jenis arsitektur terakhir juga pernah digunakan Belanda dalam mendirikan beberapa bangunan di Medan. Bangunan bergaya geometris rata-rata dibangun sebelum 1935. Jika melihat waktu berdiri kantor pos pada 1911, diperkirakan ini merupakan bangunan era pertama yang menggunakan arsitektur geometris di Medan. Saat ini, bangunan Kantor Pos Medan telah berusia lebih dari seabad. Meski pun demikian, bangunan ini tidak banyak mengalami perubahan dari bentuk aslinya meski adanya renovasi. Bahkan sisi kanan dan kiri ukiran logo merpati pos masih terukir terompet khas Belanda pada zaman dahulu. [1]

Begitu pula fungsinya, bangunan ini masih tetap digunakan sebagai kantor pos dengan berbagai aktivitas pelayanan jasa pengiriman. Inilah salah satu bangunan bersejarah di Medan yang masih tetap bertahan di antara perubahan zaman.

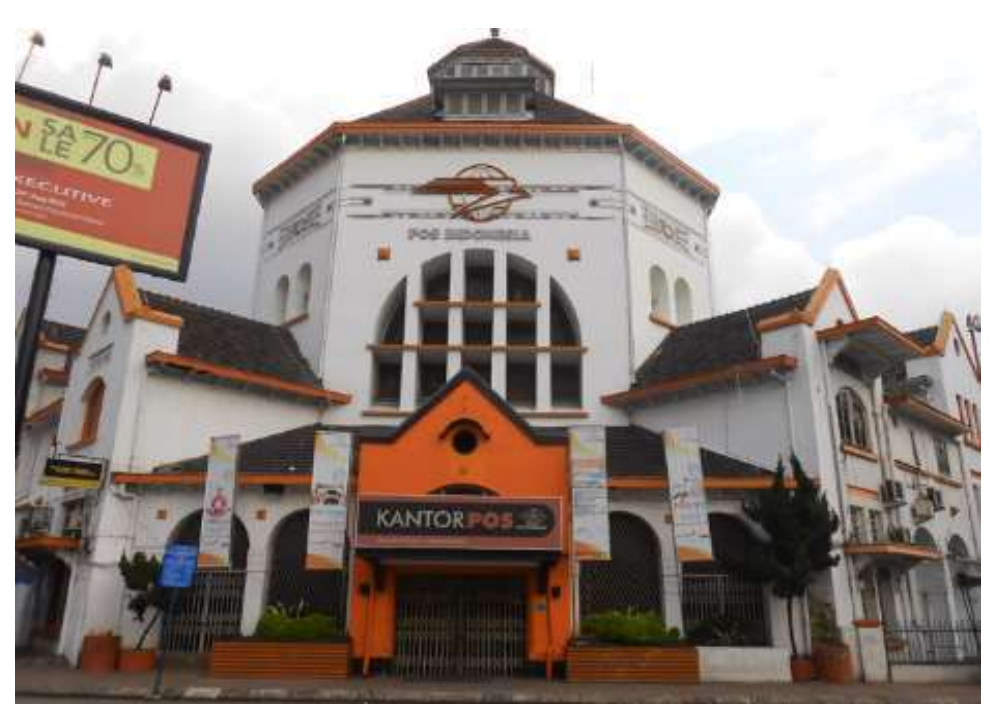

Gambar 4 : Kantor Pos Besar Medan Sumber : Juli Atika, 2018

Bangunan ini dibangun sebagai fungsi kantor pos dari awal berdirinya hingga saat ini, kondisi bangunan ini masih terawat dengan baik. Diatas bangunan tersebut bertuliskan ANNO 1911 yang menjadi salah satu bukti tahun dibangunnya kantor pos besar Medan. Bangunan ini merupakan proyek besar pertama dilakukan oleh Ir. Simon Snuyf, seorang arsitek yang telah menjadi kepala Sipil Pekerjaan Umum untuk Hindia-Belanda saat itu (Suhanda, 2013). Bangunan bersejarah ini memiliki atap langit -langit yang tinggi dan struktur bangunan yang kokoh serta ruangan yang cukup luas. Selain itu, bangunan bersejarah ini memiliki aspek historis yang kental terutama dari segi bentuk arsitektur bangunannya yang sangat terlihat bahwa bangunan ini sudah sangat lama dan berbeda sekali dengan bangunan-bangunan modern yang ada terdapat disekelilingnya. Ketika dilihat dari dalam ruangan maupun di luar ruangan, bangunan kantor pos ini terlihat sangat menarik untuk dilihat karena bentuknya yang unik (Suhanda, 2013). [1] 
Terdapat bangunan kantor pos medan yang memiliki banyak ornamen-ornamen bersejarah, peneliti membuat sebuah kajian terhadap bangunan interior pada kantor pos dan bangunan tersebut tidak di bahas lebih jauh mengenai kajian interiornya tetapi peneliti hanya mengkaji berbagai bangunan interior yang terdapat disalah satu ruang yang terdapat di ruang kantor pos medan, salha satu pembahasan yang akan dibahas peneliti adalah bagian pada ruang tengah yang terdapat pada kantor pos.

Hiasan puncak atap pada bangunan kantor pos besar Medan ini terdapat pada ujung atap pada bagian menara segi enam bangunan tesebut, Hiasan tersebut berbentuk tiang yang memanjang ke atas dan disertai bentuk persegi diujung tiang tersebut. Hiasan puncak atap ini merupakan salah satu elemen-elemen arsitektural kolonial Belanda di HindiaBelanda.

Burung merpati diatas merupakan ragam hias bangunan dalam pada kantor pos besar Medan. Burung merpati sebagai logo pos pertama dengan desain Belanda kuno yang menghiasi setiap sisi dinding ruang tengah atau disebut vestibule yang merupakan tower dengan sisi segi enam pada bangunan kantor pos besar Medan.

Kaca Patri berukuran besar inilah yang menghiasi ruang tengah yang disebut vestibule. Kaca berukuran besar dengan setengah lingkaran ini merupakan desain Belanda kuno yang sudah ada sejak awal berdirinya bangunan kantor pos besar Medan. [1]

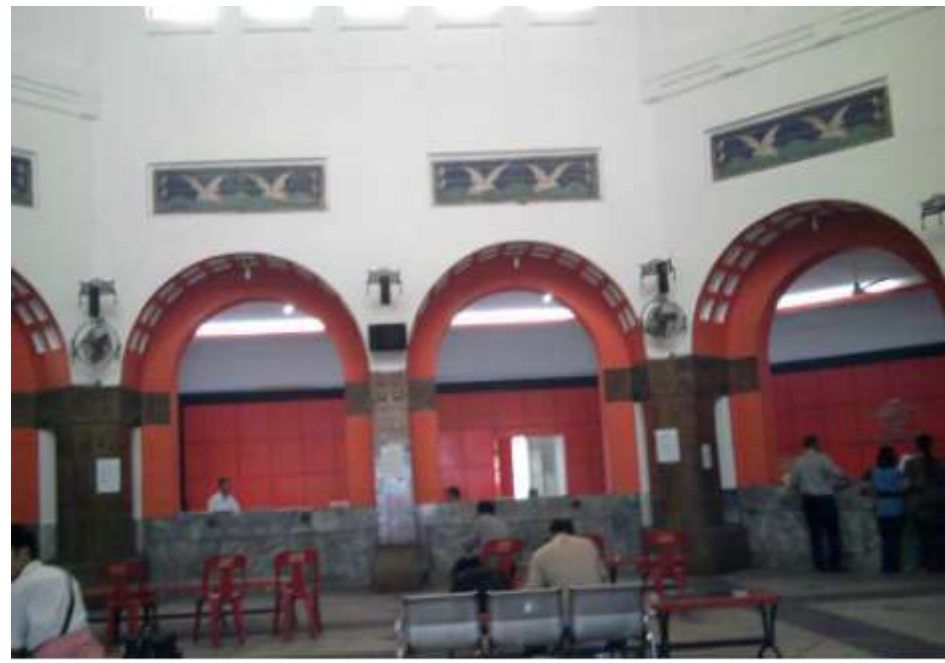

Gambar 5 : Ruang Tunggu Tamu

Sumber : Juli Atika, 2018

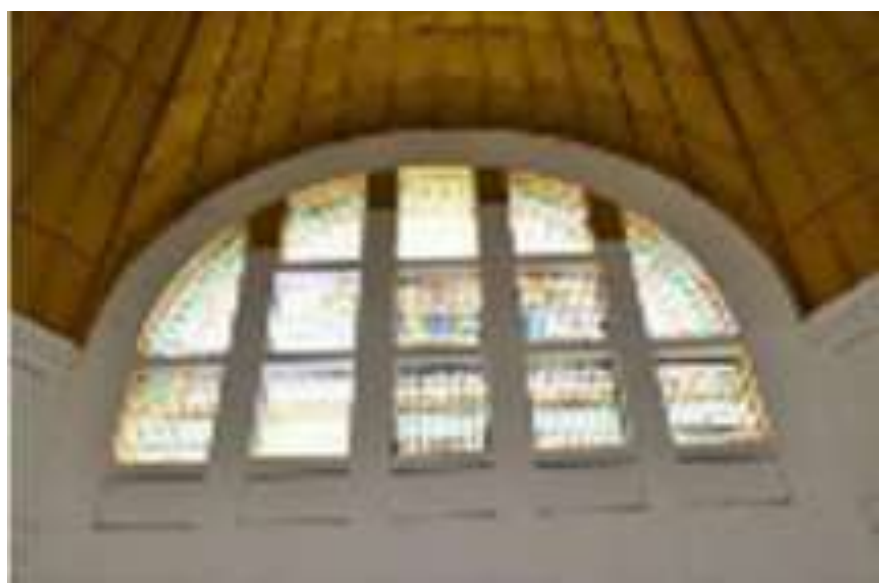

Gambar 6 : Kaca Patri

Sumber : Juli Atika, 2018 
Kubah besar pada kantor pos besar Medan ini berada di ruang tengah (vestibule). Kubah ini berbentuk segi delapan dengan balutan kuningan asli yang menghiasi langitlangit kubah tersebut. Namun, lapisan itu mengelupas akibat tragedi kebakaran yang sempat menghanguskan sebagian kecil bangunan kantor pos pada Juni 2003. Kebakaran yang disebabkan oleh hubungan pendek arus listrik itu merusak lampu hias dan ornamen di langit-langit. Kerusakan yang terjadi tidak signifikan. [1]

Pihak kantor pos sendiri telah mengembalikannya ke bentuk dan warna aslinya sehingga terlihat seperti lampu pada belanda.

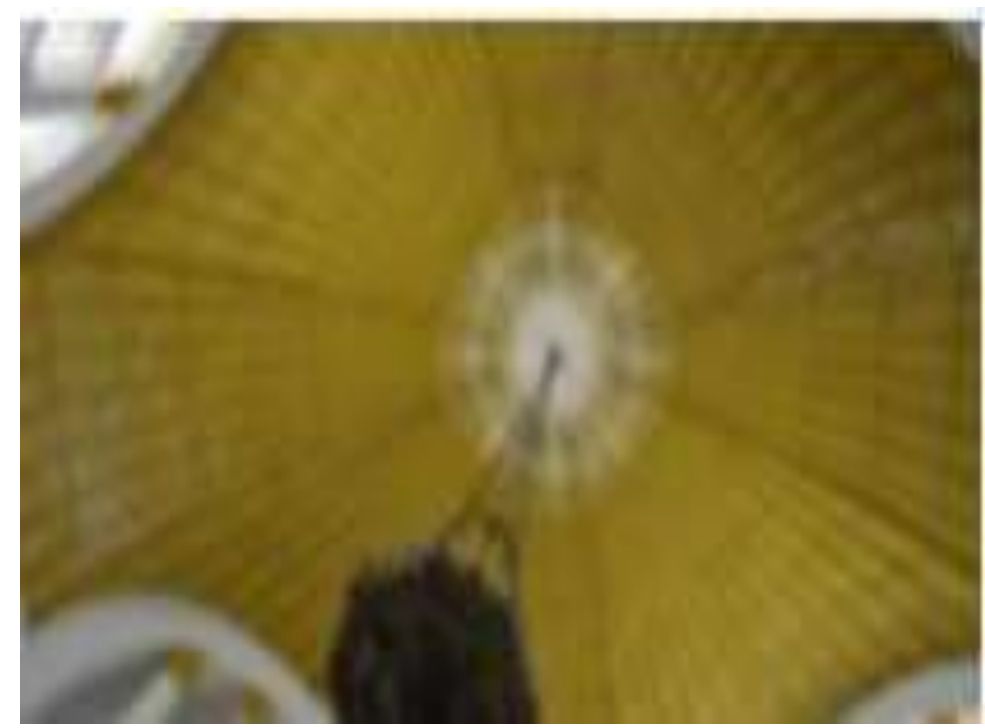

Gambar 7 : Kubah didominasi Warna Kuning Emas Sumber : Juli Atika, 2018

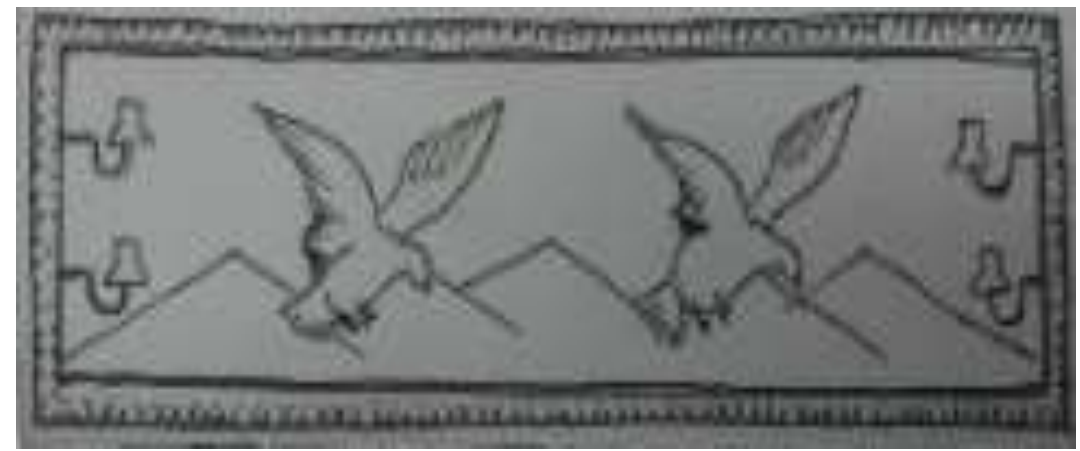

Gambar 8 : Burung Merpati Hiasa Puncak Atas

Sumber : Juli Atika, 2018 


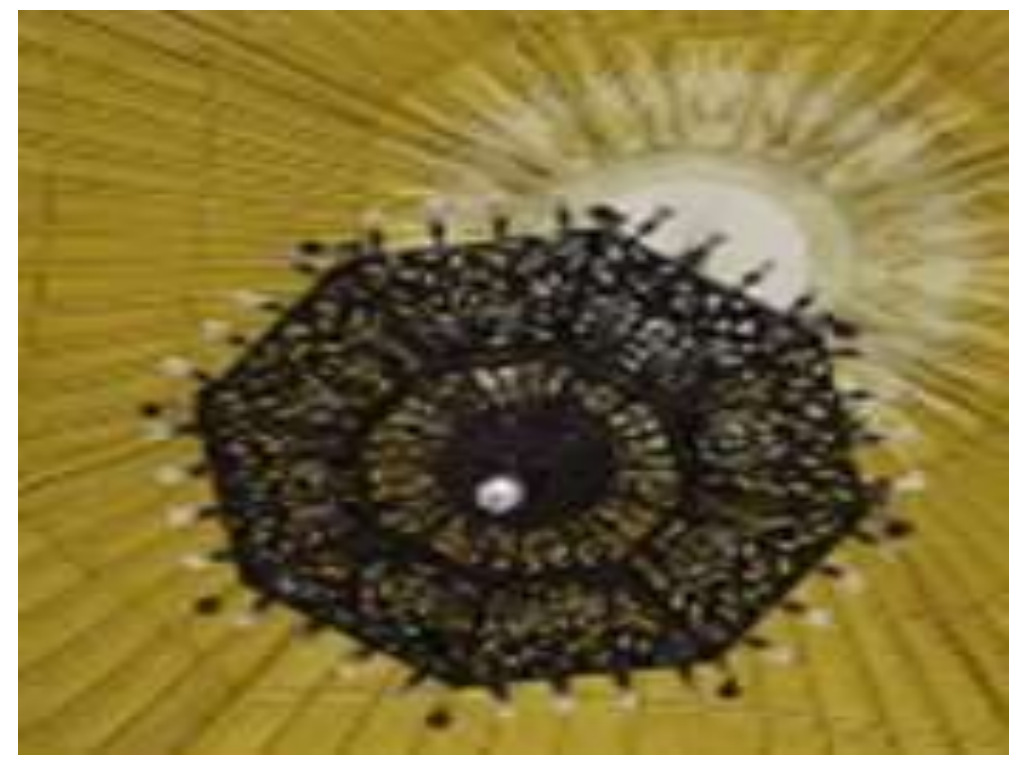

Gambar 9 : Lampu Hias Antik

Sumber : Juli Atika, 2018

Di ruang tengah, yang disebut vestibule, pada bagian atas tergantung lampu hias antik khas zaman dulu. Lampu setinggi lebih kurang sepuluh meter dan berada pada ketinggian sekitar enam meter dari lantai tersebut masih asli dari zaman Belanda sehingga lampu tersebut terbentuk labih menarik.

\section{KESIMPULAN}

Kantor pos Medan merupakan bangunan kolonial yang dirancang oleh Ir. Simon Snuyf. Pada perancangannya, bangunan ini juga dibuat dengan tujuan sebagai tempat berkumpul, dapat ditinjau dari interior ruang tengahnya (vestibule). Ruang tengah ini juga berperan penting sebagai bagian fasade utama pada bangunan kantor pos jika ditinjau dari interiornya. Ruang tengah kantor pos Medan juga memiliki sisi segi delapan yang memanjang ke atas membentuk tower. Tower merupakan salah satu ciri khas dari konsep arsitektur kolonial Belanda, kemudian dilengkapi dengan hiasan puncak atap untuk memperindah bangunan. Sampai saat ini, kantor pos Medan masih menjalankan fungsinya dengan baik.

Kantor Pos pada masa kini selalu menjadi tempat bersejarah di kawasan kota medan serta kantor pos ini tempat pengiriman barang pada saat indonesia masih dijajah oleh negara belanda sampai saat ini pun masyarakat seluruh indonesi masih banyak yang menggunakan jasa dari pos Indonesia. 


\section{DAFTAR PUSTAKA}

[1] Arsitektur Institut Teknologi Bandung. 2017. Prosiding Seminar Heritage IPLBI.

Online :

[2] https://dewakencana1404205068.wordpress.com/2016/09/15/pengertian-dasar-desaininterior/

[3] http://library.binus.ac.id/eColls/eThesisdoc/Bab2/2014-2-00422-DI\%20Bab2001.pdf

[4] https://biancabfy.files.wordpress.com/2017/09/teori-umum-interior.pdf 